\title{
Pneumocystis jiroveci: Epidemiology and diagnosis
}

\author{
Zineb Tlamçani ${ }^{1}$, Mohammed Er-Rami ${ }^{2}$ \\ ${ }^{1}$ Laboratory of Peripheral Hospital Center, Taroudant, Morocco. \\ ${ }^{2}$ Department of Parasitology, Faculty of Medicine and Pharmacy of Fes, Morocco.
}

Corresponding Author Zineb Tlamcani

E mail:

Tzineb@hotmail.fr

Key words: Pneumocystis jiroveci, Pneumocystis pneumonia, immunodeficiency.
The Pneumocystis organism was initially described in 1909 by Chagas. Pneumocystis jiroveci is an uncommon opportunistic organism, which induces a severe and mostly fatal pneumonia in immunocompromised people. Pneumocystosis comes from reactivation of latent infection acquired while childhood or active acquisition while immunosuppression state. The epidemiology of Pneumocystis pneumonia (PCP) has changed considerably through the course of the HIV/AIDS epidemic. The establishments of PCP prophylaxis in 1989 and effective combination antiretroviral therapy in 1996 , have resulted in substantial reduces

\section{INTRODUCTION}

Pneumocystis jiroveci is an uncommon opportunistic organism, which induces a severe and mostly fatal pneumonia in immunocompromised people [1]. The Pneumocystis organism was initially described in 1909 by Chagas in Guinea pigs, and after that by Carini in rat lung [2]. Until 1980 Pneumocystis pneumonia (PCP) was unusual and primarily noticed in association with syndromes of immunodeficiency or intensive immunosuppression, particularly cancer chemotherapy. With the HIV-1 pandemic, however, PCP become the major AIDS defining disease in developed countries[3]. Pneumocystis jiroveci, consequently, continues to be an organism of clinical significance in today's practice [4]

\section{ORGANISM}

Pneumocystis organisms were primarily known and named Pneumocystis carinii at the beginning of last century [5]. In 2002, human Pneumocystis organism was recalled in the incidence of PCP. Due to the insufficient specificity of clinical symptoms as well as the possibility of toxicity with therapy, the affirmation of PCP is important details for correct patient management. The traditional method for diagnosis of PCP depends on the microscopic visualization of organisms in respiratory samples. PCR diagnosis of $P$. jiroveci was introduced experimentally in 1990. Molecular methods, could detect $P$ jirovecii DNA in respiratory samples from patients without clinically apparent PCP. In this review both epidemiology and diagnosis of Pneumocystis jiroveci will be discussed.

Pneumocystis jiroveci by the identification of its genetic and functional distinctness, in honour of Otto Jirovec, who is recognized for identifying the microbe in humans $[6,7]$.

Pneumocystis was for an extended time defined as a protozoe according to morphologic features and the resistance to classical antifungal agents. Then again, in the late eighties, $P$. carinii was positioned in the fungal kingdom depending on phylogenetic analysis of ribosomal RNA (rRNA) sequences and observations of genome size. [8]. The organism has currently been fixed in a group of fungi entitled the Archiascomycetes. [9]

In the lung, two main forms of the organism could be identified by microscopy: They are usually called cystic form (cysts) and trophic form (trophozoites), however they more appropriately, considering the fungal reclassification, might be defined as sporangium and yeast cells[10] . 
The cystic form (sporangium) is usually thickwalled oval, about 5 to $8 \mu$ in diameter and include approximately eight daughter forms (spores or endospores, initially called intracystic bodies or sporozoites), which will eventually become trophic forms after excystation. The trophic form (yeast, previously trophozoite) is small $(2$ to $5 \mu \mathrm{m})$, thin-walled, pleomorphic and commonly has an eccentric nucleus. The trophic forms are usually seen in clusters. A third form, the precyst, is infrequently encountered, but is believed to constitute an intermediate stage. There is no precise knowledge of the lifecycle as well as the mode of replication has not been absolutely demonstrated, but both asexual and sexual life cycles have been suggested according to electromicrographic observations of synaptonemal complexes $[11,12]$

\section{TRANSMISSION}

\section{Reactivation of Latency}

Traditional concepts have retained that pneumocystosis comes from reactivation of latent infection acquired while childhood. Detectable antibodies are found in most of children by four years of age. Moreover, presence of $P$. jiroveci in respiratory samples from clinically normal population sustains the reactivation theory [13,14]. Besides, host immune evasion by variation of major suface glycoprotein (MSG), species specificity of $P$. jiroveci and complicated in vitro cultivation are constant with extended carriage or latency in the host 15,16$]$.

\section{Active Acquisition}

Almost all attempts to transfer $P$. jiroveci from one animal species to another have been failed. In natural environment, $P$. jiroveci deoxyribonucleic acid (DNA) has been found in water, air and in soil samples, however, whole organism has been practically never recognized from these sources. Navin et al [17] discovered that patients with $P$. jiroveci were usually have history of recent gardening, therefore suggesting soil exposure. Outbreaks in oncology and transplant units have increased the possibility of person to person transmission. Besides clinical cases, sub-clinical cases and a few number of immunocompetent persons with no evidence of clinical disease accommodate $P$. jiroveci, forming the reservoir. This source should not be disregarded without the presence of other evidences. In any case, the transmission occurs via an airborne route as alveolus is the site of infection. The vertical transmission is rarely reported and it couldn't be demonstrated by animal experiments [18].

\section{EPIDEMIOLOGY}

The epidemiology of PCP has changed considerably through the course of the HIV/AIDS epidemic. In the 1980s, PCP was the AIDS defining disease for about two-thirds of adults and adolescents with AIDS in the United States, and it was supposed that $75 \%$ of HIVinfected persons would acquire PCP through their lifetime [19]. At the beginning of the epidemic, the incidence of Pneumocystis pneumonia was approximately 20 cases per 100 person-years in HIV-infected persons with CD4+ cell counts under 200 cells/l [20]. The establishments of PCP prophylaxis in 1989 and effective combination antiretroviral therapy in 1996 have resulted in substantial reduces in the incidence of Pneumocystis pneumonia. In the Centers for Disease Control and Prevention (CDC) Adult and Adolescent Spectrum of Disease (ASD) Project, the incidence of Pneumocystis pneumonia declined $3.4 \%$ per year for the period from 1992 to 1995 and then decreased $21.5 \%$ annually during 1996 to 1998 , a time when effective combinations of antiretroviral therapy were starting to be applied [21]. In the Euro SIDA study, the incidence of Pneumocystis pneumonia reduced from 4.9 cases per 100 person-years before March 1995 to 0.3 cases per 100 person-years after March 1998 [22]. Even with its decreased incidence, PCP continues to be the common serious opportunistic infection among HIV-infected persons, and a considerable proportion of persons who develop Pneumocystis pneumonia are unconscious of their HIV infection or are outside of medical care, consequently minimizing opportunities for additional reductions in the incidence of the disease. A consideration, Pneumocystis pneumonia has been significantly reported in low- or middle-income countries (LMIC). One clinical study from Uganda observed that $38.6 \%$ of $83 \mathrm{HIV}$-infected patients who were admitted to the hospital with pneumonia and who had three expectorated sputum smears which were negative for acidfast bacilli had Pneumocystis pneumonia detected on bronchoscopy with bronchoalveolar lavage (BAL) $[23,24]$. 


\section{DIAGNOSIS}

\section{CLINICAL DIAGNOSIS}

The fungal pathogen Pneumocystis jirovecii is the source of PCP in humans [25]. Patients with PCP generally present non-specific respiratory symptoms, such as dyspnea, cough, and fever. Immunocompromised hosts commonly present a triad of progressive dyspnoea of many weeks, non-productive cough or with clear sputum and low-grade fever. They are more apt to be in respiratory distress coupled with severe hypoxemia [4]. On medical exam, tachypnoea, tachycardia, cyanosis and fine dry rales can be present [2]. While extrapulmonary involvement is exceptional, eye, ear, spleen, bone marrow, lymph node, liver, and meningeal involvement, have been mentioned [4].

Chest X-ray generally reveals diffuse interstitial or peri-hilar reticulonodular infiltrates but could be normal in one-third of cases. Other findings, including spontaneous pneumothorax, effusions or cavitary lesions may be seen in few numbers of cases [26].

\section{BIOLOGICAL DIA GNOSIS}

Due to the insufficient specificity of clinical symptoms as well as the possibility of toxicity with therapy, affirmation of PCP is important an essential details for correct evidence-based patient management [1]. Diagnosis of $P$ jirovecii infection is hampered by the lack of a sustainable in vitro culture method. Elevated serum lactate dehydrogenase $(\mathrm{LDH})>460 \mathrm{IU} / \mathrm{L}$ has been noticed to be a sensitive test for this disease, but a variety of pathological conditions involving lungs indicate increased serum LDH level. Measurement of partial pressure of arterial oxygen $(\mathrm{PaO} 2)$ gives a perfect negative predictive value for exemption of $P$. jiroveci infection as $\mathrm{PaO} 2<75 \mathrm{mmHg}$ correlates with the illness [27, 28].

\section{Conventional methods}

The traditional method for diagnosis of PCP depends on the microscopic visualization of $P$. jiroveci organisms in respiratory samples. Given that only a few organisms can be found within the upper respiratory tract, lower respiratory secretions are often essential for certain diagnosis. Bronchoalveolar lavage (BAL) coupled with colorimetric as well as an immunofluorescent stain of BAL fluid is recognized as the technique of choice with sensitivity and specificity more than $95 \%$. A different option is evaluation of material gotten by induced sputum. In spite of this, the sensitivity of that method is much more based on the experience of the personnel executing the procedure and checking the samples, with elevated variation in the diagnostic sensitivity noted (between 50 to 90\%) [29,30,31,32] .

The usage of cytochemical stains for diagnosis is very slow process, and it could be complicated to preserve laboratory diagnostic expertise due to the reduced incidence of PCP after the introduction of significantly active antiretroviral therapy $[33,34]$.

\section{PCR methods}

Since BAL is an invasive and irritating procedure that is not without risk, other noninvasive test were approved. PCR diagnosis of $P$. jiroveci was introduced experimentally in 1990 once Wakefield et al first identified DNA amplification of the multicopy mitochondrial ribosomal RNA gene. Since that time, numerous studies have evaluated PCR detection of Pneumocystis DNA in respiratory samples from HIV-1 positive and negative patients. To improve the diagnostic sensitivity of non-BAL specimens, distinct PCR methods have been considered, such as different gene targets and the use of nested PCR, during which a second round of PCR reamplifies the primary PCR product [1]. Molecular methods, on the other hand, could detect $P$ jirovecii DNA in respiratory samples from patients without clinically apparent PCP [35,36] advocating asymptomatic carriage or "colonisation". Real-time PCR permits appropriate quantification of DNA as well as possibility to discriminate between asymptomatic carriage of $P$ jirovecii and clinical disease depending on pathogen load.

\section{CONCLUSION}

$P$ jirovecii is pathogen fungal organism witch continues to be an organism of clinical significance in today's practice and should not be disregarded because of the close link between this disease and HIV-infected persons. An earlier diagnosis with appropriate method could improve the prognosis of PCP and the correct patient therapy management. 


\section{REFERENCES}

1. Helweg-Larsen J. Pneumocystis jiroveci Applied molecular microbiology, epidemiology and diagnosis.Dan Med Bull 2004;51:251-73.

2. Redhead SA, Cushion MT, Frenkel JK, Stringer JR. Pneumocystis and Trypanosoma cruzi: nomenclature and typifications. $J$ Eukaryot Microbiol 2006;53:2-11

3. Chaisson RE, Keruly J, Richman DD, Moore RD. Pneumocystis prophylaxis and survival in patients with advanced human immunodeficiency virus infection treated with zidovudine. The Zidovudine Epidemiology Group. Arch Intern Med 1992; 152(10):2009-2013.

4. Juliana Li, Andrew McIvor, Pneumocystis jiroveci Pneumonia: Not a Disease of the Past; MUMJ 2012 ; $9: 1$.

5. Delanoe P, Delanoe M. Sur les supports des kystes Pneumocystis carinii du poumon des rats avec Tryponosoma lewisi. $C R$ Acad Sci (Paris)1912; 155:658-660.

6. Frenkel JK. Pneumocystis pneumonia, an immunodeficiency-dependent disease (IDD): a critical historical overview. J Eukaryot Microbiol 1999; 46(5):89S-92S.

7. Stringer JR, Beard CB, Miller RF, Wakefield AE. A New Name (Pneumocystis jiroveci) for Pneumocystis from Humans. Emerg Infect Dis, 2002; 8(9):891-896.

8. Lundgren B, Cotton R, Lundgren JD, Edman JC, Kovacs JA. Identification of Pneumocystis carinii chromosomes and mapping of five genes. Infect Immun 1990; 58(6):1705-1710.

9. Haase G. Pneumocystis carinii Delanoe and Delanoe (1912) has been placed in the Archiascomycetales, a class of the Ascomycota. Infection and Immunity 1997; 65(10):4365-4366.

10. Schuh JC, Harrington KA, Fanslow WC. Terminology changes needed for descriptions of Pneumocystis carinii infection. Infect Immun 1997; 65(3):1135-1136.

11. Cushion MT, Ruffolo JJ, Walzer PD. Analysis of the developmentalstages of Pneumocystis carinii, in vitro. Lab Invest 1988; 58(3):324-331.

12. Matsumoto Y, Yoshida Y. Sporogony in Pneumocystis carinii: synaptonemal complexes and meiotic nuclear divisions observed in precysts. J Protozool 1984; 31(3):420-428.

13. Morris A, Beard CB, Huang L. Update on epidemiology and transmission of Pneumocystis carinii. Microbes Infect 2002; 4: 95-103.
14. Peglow SL, Smulian AG, Linke MJ, Pogue CL, Nurre S, Crisler J, et al. Serological responses to Pneumocystis carinii antigens in health and disease. J Infect Dis 1990; 161: 296-306.

15. Gigliotti F. Host species-specific antigenic variation of a mannosylated surface glycoprotein of Pneumocystis carinii. J Infect Dis 1992; 165: 329-36.

16. Gigliotti F, Harmsen AG, Haidaris CG, Haidaris PJ. Pneumocystis carinii is not universally transmissible between mammalian species. Infect Immun 1993; 61: 2886-90.

17. Kaplan JE,Masur H, Holmes KK. Guidelines for preventing opportunistic infections among HIVinfected persons-2002. Recommendations of the U.S. Public Health Service and the Infectious Diseases Society of America. MMWR Recomm Rep 2002;51:1-52.

18. R. Singhal, B.R. Mirdha and R. Guleria,Human Pneumocystosis.The Indian Journal of Chest Diseases \& Allied Sciences 2005; 47:273-284.

19. Hay JW, Osmond DH, Jacobson MA. Projecting the medical costs of AIDS and ARC in the United States. $J$ Acquir Immune Defic Syndr 1988;1:466-485.

20. Phair J, Munoz A, Detels R, Kaslow R, Rinaldo C, Saah A. The risk of Pneumocystis carinii pneumonia among men infected with human immunodeficiency virus type 1. Multicenter AIDS Cohort Study Group. N Engl J Med 1990; 322:161-165.

21. Kaplan JE, Hanson D, Dworkin MS, Frederick T, Bertolli J, Lindegren ML,et al. Epidemiology of human immunodeficiency virus-associated opportunistic infections in the United States in the era of highly active antiretroviral therapy. Clin Infect Dis 2000; 30:S5-14.

22. Weverling GJ, Mocroft A, Ledergerber B, Kirk $\mathrm{O}$, Gonzales-Lahoz J, d'Arminio Monforte A, et al. Discontinuation of Pneumocystis carinii pneumonia prophylaxis after start of highly active antiretroviral therapy in HIV-1 infection. EuroSIDA Study Group. Lancet 1999;353:12931298.

23. Worodria W, Okot-Nwang M, Yoo SD, Aisu T. Causes of lower respiratory infection in HIVinfected Ugandan adults who are sputum AFB smear-negative. Int $J$ Tuberc Lung Dis 2003;7:117-123. 
24. Laurence Huang, Alison Morris, Andrew $\mathrm{H}$. Limper, and James M. Beck. Recent Advances and Future Directions in Pneumocystis Pneumonia (PCP).American Thoracic Society Documents 2006(3):655-664.

25. Wilkin A, Fienberg J. Pneumocystis carinii pneumonia: a clinical review. Am Fam Physician 1999; 60: 1699-708

26. Opravil M, Marincek B, Walter AF, Weber R, Speich R, Battegay M, et al. Shortcomings of chest radiography in detecting Pneumocystis carinii pneumonia. J Acquir Immune Defic Syndr 1994; 7: 39-45.

27. Quist J, Hill AR. Serum lactate dehydrogenase (LDH) in Pneumocystis carinii pneumonia, tuberculosis and bacterial pneumonia. Chest 1995; 108: 415-8.

28. Thomas CF, Limper AH. Pneumocystis pneumonia: clinical presentation and diagnosis in patients with and without acquired immunodeficiency syndrome. Semin Respir Infect 1998; 13: 289-95.

29. Elvin KM, Bjorkman A, Linder E, Heurlin N, Hjerpe A. Pneumocystis carinii pneumonia: detection of parasites in sputum and bronchoalveolar lavage fluid by monoclonal antibodies. BMJ 1988; 297(6645):381-384.

30. Huang L, Hecht FM, Stansell JD, Montanti R, Hadley WK, Hopewell PC. Suspected Pneumocystis carinii pneumonia with negative induced sputum examination: Is early bronchoscopy useful? American Journal of Respiratory and Critical Care Medicine 1995; 151:1866-18.
31. Kovacs JA, Ng VL, Masur H, Leoung G, Hadley WK, Evans G et al. Diagnosis of Pneumocystis carinii pneumonia: improved detection in sputum with use of monoclonal antibodies. $N$ Engl J Med 1988; 318(10):589-593.

32. Metersky ML, Aslenzadeh J, Stelmach P. A comparison of induced and expectorated sputum for the diagnosis of Pneumocystis carinii pneumonia. Chest 1998; 113(6):1555-1559.

33. Wakefield AE, Pixley FJ, Banerji S, Sinclair K, Miller RF, Moxon ER, et al. Detection of Pneumocystis carinii with DNA amplification. Lancet 1990;336:451-3.

34. Caliendo AM, Hewitt PL, Allega JM, Keen A, Ruoff KL, Ferraro MJ. Performance of a PCR assay for detection of Pneumocystis carinii from respiratory specimens. $J$ Clin Microbiol 1998;36:979-82.

35. Helweg-Larsen J, Jensen JS, Dohn B, Benfield TL, Lundgren B. Detection of Pneumocystis DNA in samples from patients suspected of bacterial pneumonia: a case-control study. $B M C$ Infect Dis 2002;2:28.

36. Wakefield AE, Lindley AR, Ambrose HE, Denis CM, Miller RF. Limited asymptomatic carriage of Pneumocystis jiroveci in human immunodeficiency virus-infected patients. $J$ Infect Dis 2003;187:901-8.

Peer reviewer :Hamed Suliman: Professor of Tropical Medicine, Zagazig University, Egypt. Editor : Tarik Zaher: Professor of Tropical Medicine, Zagazig University. 